\title{
Trabajo Social y complejos sociales: aportes para pensar los procesos de intervención profesional
}

\section{Social work and social complexities: contributions for pondering the professional intervention processes}

\author{
Sergio Daniel Gianna \\ Licenciado en Trabajo Social (Escuela de Trabajo Social, Universidad Nacional de Córdoba), Magister en Trabajo Social (Facultad \\ de Trabajo Social, Universidad Nacional de La Plata) y Doctorando en Ciencias Sociales (Facultad de Ciencias Sociales, Universi- \\ dad de Buenos Aires). Becario de investigación CONICET (Consejo Nacional de Investigaciones Científicas y Técnicas). \\ Correo electrónico: sdgianna@gmail.com
}

\begin{abstract}
Resumen
Este trabajo, realizado en el marco de los estudios doctorales de posgrado, presenta algunos de los resultados alcanzados hasta el momento en torno a la relación entre el Trabajo Social, la categoría trabajo y los complejos sociales. Mediante el pensamiento de Georg Lukács, se busca reflexionar sobre el trabajo en cuanto actividad fundante del ser social y su distinción con los complejos sociales, cuya finalidad es actuar sobre las relaciones sociales. A partir de estos debates, se busca comprender por qué el Trabajo Social es un complejo social y cómo mediante la aprehensión de sus particularidades, es posible desarrollar posiciones teleológicas que apunten a la construcción de estrategias de intervención profesional que superen la inmediatez y las meras demandas institucionales.

Palabras clave. Trabajo Social - Complejos sociales - Intervención profesional - Teleología.

Summary

This work, carried out within the postgraduate doctoral study framework, shows some of the results achieved up to now concerning the relationship between Social Work, job category and social complexities. Through the judgment of Georg Lukács, we seek to reflect about work as a foundational activity of social being and its distinction with social complexities, which aim to act on social relationships. As from these discussions, the intention is to understand why Social Work is a social complexity and how, through the apprehension of its peculiarities, teleological attitudes aiming to build professional intervention strategies overcoming promptness and the mere institutional claims may be developed.
\end{abstract}

Key words. Social Work - Social complexes - Professional intervention - Teleology.

\section{Introducción}

El presente artículo, tiene por objetivo recuperar los aportes teóricos de G. Lukács en torno al trabajo y los complejos sociales, como categorías fecundas para reflexionar sobre los procesos teleológicos de la intervención profesional de los trabajadores sociales, que posibilitan la construcción de estrategias de intervención que superan las capas epidérmicas y fenoménicas de los fenómenos sociales a los que el profesional se enfrenta cotidianamente.

Para ello, se prevé en un primer momento presentar algunas de las determinaciones esenciales de la categoría trabajo en cuanto modelo de la praxis social
(Lukács, 2004). Es decir, se pretende analizar como el individuo humano mediante el trabajo realiza un salto ontológico de un ser orgánico-natural al ser social, constituyéndose en un ser onto-creador, que a partir de la transformación de la naturaleza -y de sí mismo- produce una creciente reproducción ampliada, ya que la satisfacción de una "...primera necesidad, la acción de satisfacerla y la adquisición del instrumento necesario para ello conduce a nuevas necesidades..." (Marx y Engels, 1959, p. 28). En este momento, también se prevé analizar el surgimiento de los complejos sociales y cuáles son sus particularidades respecto al trabajo. 
En un segundo momento, se presentarán algunos elementos centrales para comprender el modo de organizar el proceso de metabolismo social en el capitalismo, es decir, el modo en que se encuentra organizado el trabajo y cómo este adopta el rasgo de ser un trabajo asalariado cuyo contenido es el trabajo alienado. Durante el desarrollo de este momento, se analizarán las condiciones históricas de emergencia del Trabajo Social como complejo social, inserto en la división social y técnica del trabajo en la fase imperialista del capitalismo.

Finalmente, en un tercer momento, se busca abordar los procesos teleológicos secundarios en Trabajo Social, como categoría central que permite desarrollar estrategias de intervención que diferencien la demanda institucional de la finalidad planteada por el profesional, ampliado sus espacios de autonomía relativa.

\section{El trabajo: categoría fundante del ser social}

La génesis y desarrollo del hombre como ser social es, para Lukács (2004), el resultado de un salto ontológico, que desde las bases de la naturaleza orgánica produce una ruptura con ésta, emergiendo un nuevo nivel del ser cualitativa y estructuralmente distinto. En palabras del autor, "el camino de la evolución es el de la supremacía máxima de las categorías específicas de una esfera vital sobre aquellas que obtiene su existencia y efectividad, de manera ineludible, a partir de la esfera anterior" (Lukács, 2004, p. 56).

Es decir, esta supremacía de una esfera del ser sobre otra denota la esencia del salto ontológico en cuanto proceso de ruptura con la continuidad rectilínea del anterior nivel del ser a partir de la cual emerge un ser cualitativa y estructuralmente distinto. Según Lukács (Kofler y otros, 1971), la estructura del ser posee tres formas fundamentales: la inorgánica, la orgánica y la social. Si bien cada una de estas esferas ontológicas (Lessa, 2007a) posee una relación permanente entre sí -por ello la realidad es un "complejo de complejos"- las mismas conservan una "relativa autonomía".

Por lo tanto, la totalidad concreta está compuesta por complejos ontológicos cuyas procesualidades son particulares, expresándose estas diferencias cualitativas del salto ontológico entre los niveles del ser. Así, la naturaleza inorgánica es una esfera sin vida, cuya procesualidad consiste en transformarse en algo distinto; el mundo orgánico tiene una dinámica epifenoménica, que se reproduce a sí misma continuamente, mientras que en la esfera social es la conciencia, en cuanto desarrollo de posiciones teleológicas, lo que distingue al ser social del mundo animal.

En ese sentido, a diferencia del mundo de la naturaleza orgánica, -donde el animal actúa de modo instintual y directo sobre el medio-, el mundo de los hombres antepone mediante la conciencia múltiples respuestas, producto de diversas alternativas ante una situación concreta. Es por ello que para Lukács el trabajo, en cuanto praxis primaria del hombre, crea "sus propias condiciones de reproducción; y, por cierto, de tal manera que la reproducción simple de lo existente en cada caso conforma solo el caso límite de la típica reproducción ampliada" (Lukács, 2004, p. 61).

Es decir, el salto ontológico entre la esfera orgánica y la social es producto del desarrollo del trabajo, en cuanto actividad que permite al hombre superar las respuestas inmediatas e instintuales sobre el medio, anteponiendo una mediación entre las necesidades humanas y la satisfacción de las mismas, a partir de un proceso de producción de valores de uso. El trabajo, de este modo, se constituye en la actividad fundante del ser social, que mediante la transformación de la naturaleza genera los valores de uso -sean del estómago o de la fantasía (Marx, 2002)- necesarios para la reproducción humana. Para Marx, "El proceso de trabajo (...) es una actividad orientada a un fin, el de la producción de valores de uso, apropiación de lo natural para las necesidades humanas, condición general del metabolismo entre el hombre y la naturaleza, eterna condición natural de la vida humana y por tanto independiente de toda forma de esa vida, y común, por el contrario, a todas sus formas de sociedad" (2002, p. 223).

Lo señalado por Marx permite inferir, por un lado, el carácter universal y esencial que tiene el intercambio del hombre con la naturaleza para su reproducción biológica y social, siendo el trabajo la actividad fundamental a partir del cual el individuo organiza el proceso de producción y reproducción de la vida social, ya que sin este no habría vida humana; por el otro, que todo acto de trabajo es una actividad puesta orientada por una finalidad, donde "al consumarse el proceso de trabajo surge un resultado que antes del comienzo de aquel ya existía en la imaginación del obrero, osea idealmente. El obrero no solo efectúa un cambio de forma de lo natural; en lo natural, al mismo tiempo, efectiviza su propio objetivo, objetivo que él sabe que determina, como una ley, el modo y manera de su accionar y al que tiene que subordinar su voluntad" (Marx, 2002, p. 216). Es a partir de un proceso teleológico, que es siem- 
pre puesto -ya que implica la posición de un fin y una conciencia que coloca fines-, que el trabajo transforma la naturaleza, produciendo una nueva objetividad, que al mismo tiempo, conserva sus fundamentos ontológico-naturales. Mediante esta posición teleológica, que implica un proceso de determinación de los fines e investigación de los medios para alcanzar dicha finalidad, es que se busca convertir la causalidad -en cuanto "movimiento autónomo basado en sí mismo" (Lukács, 2004, p. 63) - en una causalidad puesta.

La teleología, de este modo, es un momento del trabajo que antecede y dirige la acción y a partir de la cual son anticipadas en la conciencia las acciones y los resultados de las mismas. Recuperando a Aristóteles, Lukács (2004) señala que el proceso de trabajo supone dos componentes, el acto de pensar y producir. Complejizando esta posición a partir de Hartmann, el primer componente incluiría dos dimensiones, la concreción de la determinación del fin y la investigación de los medios.

Este proceso de investigación de los medios busca aprehender las cualidades y determinaciones de aquellos objetos y cadenas causales necesarias para la consecución del fin planteado. Es decir, supone un conocimiento objetivo en torno a la causalidad para actuar sobre ella y transformarla. Para Lukács, "la investigación tiene, en ello, una doble función: por un lado, revela lo que se halla presente en sí en los objetos en cuestión, independientemente de toda conciencia; por otro, descubre en los objetos nuevas combinaciones, nuevas posibilidades de función, a través de cuya puesta en movimiento puede únicamente ser realizado el fin teleológicamente puesto" (2004, p. 70).

La realización exitosa o el fracaso del trabajo dependerán en gran medida del grado de aprehensión de las cadenas causales necesarias para transformar la realidad y producir una nueva objetividad. En ese sentido, la teleología desarrolla un reflejo de la realidad, donde el sujeto, mediante la conciencia, reproduce objetos que son externos a él, constituyéndose la relación sujeto-objeto, como unidad no identitaria entre el individuo humano y la realidad exterior. Es por ello, que "en el reflejo de la realidad, la reproducción se separa de la realidad reproducida, se cristaliza en una 'realidad' propia dentro de la conciencia. Hemos puesto entre comillas la palabra realidad, ya que en la conciencia la realidad es meramente reproducida; surge una nueva forma de objetividad, pero no una realidad; y lo reproducido no puede ser semejante, y aun menos idéntico a aquello que se reproduce" (2004, p. 83-84).
El reflejo, por lo tanto, permite al individuo conocer la realidad a partir de la finalidad propuesta, descubriendo en la realidad sus cualidades y determinaciones, es decir, sus posibilidades, que mediante una cadena de alternativas el individuo lleva a la práctica. A partir de la objetivación, que no es más que el proceso de transformación de la realidad, se vuelve la causalidad dada en una causalidad puesta. Este proceso de objetivación enfrenta al individuo a una situación concreta con cadenas causales concretas, debiendo elegir entre diversas alternativas para la consecución de la finalidad propuesta.

En otras palabras, la teleología -que determina la finalidad del acto del trabajo y los medios acordes para la consecución del mismo- permite orientar el pasaje de la posibilidad, en cuanto proyecto ideal de la finalidad a alcanzar, a la realidad, proceso que enfrenta al individuo a una serie de alternativas concretas dentro de una situación específica y particular. Es decir, lo que orienta al trabajo es un deber ser (Lukács, 2004) en el cual las diversas acciones emprendidas en el proceso de trabajo se orientan a favorecer la consecución de la finalidad planteada.

Este proceso de transformación de la realidad, pasaje en el cual la teleología busca actuar sobre la causalidad, es el momento en el cual el trabajo humano se objetiva, donde se produce la articulación y encuentro entre la teleología, -en cuanto previa ideación-, y la materialidad de la realidad. Mediante la objetivación del trabajo humano, la realidad comienza a ser transformada por el propio hombre, constituyéndose de este modo, el mundo de los hombres (Lessa, 2002).

Sin embargo, como advierte Marx (2002), este proceso de transformación de la naturaleza también impacta en la propia naturaleza humana, modificándola. Esta transformación refiere a la exteriorización, en el cual aquel hombre individual que realizó el proceso de trabajo y la sociedad en la que se encuentra ya no es la misma luego de este acto de trabajo, por un lado, porque los límites entre lo conocido y lo desconocido se han modificado (Lessa, 2000), por el otro, porque el hombre ha avanzado en el dominio conciente y racional de la realidad, para poder actuar sobre ella.

Como advierte Lessa (2002), tanto la objetivación como la exteriorización son momentos de una misma procesualidad: el trabajo, siendo la primera la transformación de la realidad a partir de la teleología y la segunda, una instancia de retorno de la objetivación sobre el individuo, sobre su subjetividad. De este modo, el trabajo inicia un proceso de transformación que no se limita únicamente a 
la realidad objetiva, sino que también impacta en el propio individuo, fortaleciendo a la conciencia como aquel órgano que permite dar respuestas que, de modo conciente y voluntario, buscan transformar la realidad.

Hasta aquí se ha intentado mostrar cómo a partir del trabajo se produce un retroceso de los "límites naturales" ${ }^{\text {- }}$-disminuyendo la incidencia de las determinaciones naturales sobre la vida humana- y dando origen a un proceso de humanización del hombre, constituyéndolo como un ser social que se distingue de la naturaleza, ya que en la esfera de la vida orgánica se produce la aparición y desaparición de nuevas especies animales y vegetales mientras que en la esfera social se desarrolla una historia, en la que surgen y perecen relaciones sociales.

Tanto el retroceso de los "límites naturales" como la constitución del ser social suponen que el intercambio entre el hombre y la naturaleza -intercambio fundamental para la vida humana- empieza a estar mediados por la sociedad, ya que "una posición teleológica provoca siempre otras posiciones teleológicas, tanto que de esto surgen totalidades complejas, las cuales hacen que la mediación entre el hombre y la naturaleza se procese cada vez más extensa, y cada vez más exclusivamente en términos sociales" (Lukács, 1981, p. 139).

Las objetivaciones de un acto de trabajo individual son la condición para la realización de otros actos de trabajo, constituyendo de este modo el mundo de los hombres. No obstante, el ser social no se limita al trabajo, sino que, teniendo a este como modelo, va produciendo una serie de objetivaciones que lo trascienden. Según Netto y Braz (2006) se ocasionan un conjunto de esferas de objetivación que tienen origen en el trabajo pero que progresivamente se van autonomizando de este. Es por ello que estos autores utilizan a la categoría praxis como algo más amplio y abarcativo, que incluye al trabajo y las diversas objetivaciones humanas.

Hasta aquí, la exposición se ha centrado en aquellas determinaciones esenciales de la categoría trabajo, siendo esta una abstracción en la medida en que el individuo humano no se encuentra aislado, sino que por el contrario, está inserto en un proceso de metabolismo social, es decir, en una malla de relaciones entre los hombres y con la naturaleza. En relación a esto, Lessa recalca que "para Lukács, el carácter de totalidad del ser es importante, porque permite divisar con claridad un momento fundamental de la procesualidad del trabajo: al insertarse en la malla de relaciones y determinaciones preexistentes, el objeto construido altera (mínimanente), desencadenando nexos causales (o sea, una secuencia de causa y efecto) que son, al mismo tiempo, 1) impregnados por momentos de causalidad y, 2) en su totalidad en el momento de la previa ideación, son imposibles de ser conocidos porque aún no acontecieron" (2007a, p. 44).

Así, el mundo de los hombres es un complejo de complejos donde predomina el trabajo y otros modos de objetivación, que Lukács (1981) llamó complejos sociales. A diferencia del trabajo, que establece un intercambio entre el hombre y la naturaleza, los complejos sociales surgen para garantizar los procesos de producción y reproducción social. Estos últimos asumen la particularidad de actuar sobre la relación hombre-hombre, constituyendo posiciones teleológicas secundarias, cuyo objeto es actuar sobre la conciencia de un hombre o de un conjunto de hombres, quienes efectivizarán el proceso de trabajo. Es decir, estos procesos teleológicos secundarios buscan "conseguir que un hombre (o un grupo de hombres) realice, por su parte, posiciones teleológicas concretas. Este problema aparece en cuanto el trabajo se ha vuelto ya a tal punto social, que se basa en la cooperación de varios hombres(...). De ahí que esta segunda forma de posición teleológica, en la cual el fin puesto es inmediatamente un fin puesto por otros hombres, ya aparezca en un nivel muy primitivo" (2004, p. 103-104).

Esta distinción entre el trabajo y los complejos sociales no supone una segmentación ni separación entre una "estructura" y una "superestructura", sino que permite captar cuál es la función social desempeñada por el trabajo y los complejos sociales, así como las particularidades que asumen en cada momento histórico. Las teleologías secundarias introducen y actúan sobre los intereses sociales, que, en el caso de las sociedades de clases, son contradictorios y antagónicos. Como recalca Lukács, "la pertenencia de clase y la participación en la lucha de clases determinan hondamente las decisiones vi-

1 Cabe aclarar que para Lukács este retroceso de los limites naturales no supone su desaparición, ya que "se trata(...)de un ininterrumpido retroceso de los límites naturales, pero nunca de la plena superación de estos; el hombre, el miembro activo de la sociedad, el motor de las transformaciones y avances de esta, sigue siendo ineludiblemente, en un sentido biológico, un ser natural: en un sentido biológico, su conciencia sigue estando ligada indisolublemente al proceso de reproducción biológica de su cuerpo, también en la sociedad se mantiene intacta la base biológica de la vida" (Lukács, 2004, p. 157). 
tales de cada miembro de la sociedad. Así, surge un ámbito de juego para los fenómenos conflictivos en cuanto el contenido de las alternativas rebasa decisivamente el metabolismo de la sociedad con la naturaleza" (2004, p. 147).

Así, los complejos sociales tienen como particularidad y funcionalidad el garantizar la reproducción social, generando una determinada forma de organización de las relaciones sociales. En la sociedad de clases, complejos sociales como el Estado, el Derecho, los medios de comunicación, son esenciales para mantener el orden social vigente y estos, procuran intervenir sobre la conciencia y sobre las alternativas concretas que los individuos realicen ${ }^{2}$ (Lessa, 2011).

El desarrollo del proceso de producción y reproducción social constituye una totalidad ("complejo de complejos") donde predomina el trabajo, en cuanto proceso de intercambio entre el hombre y la naturaleza, y diversas objetivaciones, como la ciencia, el arte, los valores éticos, entre otros, que intervienen en las relaciones entre los propios hombres. Esta unidad, que Netto y Braz (2006) sintetizan en la categoría praxis, en cuanto proceso de constitución histórica del hombre como ser social, ha atravesado diversos momentos históricos, donde los modos de organizar las relaciones humanas y con la naturaleza han mutado y cambiado. De allí que Marx y Engels (1959) recalquen que lo que son los hombres coincide con su producción -con el proceso de organización del trabajo y los valores de uso producidos- al mismo tiempo que la trasciende, ya que el modo en que se organiza el trabajo también da cuenta y refiere al proceso de reproducción biológica y social de la vida humana, es decir, al modo en que los hombres organizan su vida.

\section{Trabajo alienado y Trabajo Social}

Hasta aquí, la exposición ha intentado mostrar cómo el trabajo se constituye en el momento predominante a partir del cual se despliegan diversas determinaciones que constituyen al individuo en ser social. Sin embargo, Lukács, al inicio del capítulo del trabajo perteneciente a la Ontología del Ser Social hace algunas advertencias en torno al tratamiento teórico que se realiza sobre esta categoría: "Hay que tener siempre en claro que, con la consideración que aquí realizamos del trabajo como elemento aislado, se consuma una abstracción; la socialización, la primera división del trabajo, el lenguaje, etc., surgen sin duda del trabajo, pero no en una sucesión temporal puramente determinable, sino simultáneamente, de acuerdo con la esencia. Es, pues, una abstracción sui generis la que aquí realizamos" (2004, p. 57).

Esta abstracción, que no implica una construcción teórica de carácter valorativa por parte de Lukács, en torno al ser en general y al ser social en particular, apunta a reconocer en el trabajo no solo la praxis primaria a partir de la cual se desarrolla el individuo humano, sino también a que la misma es la base inelimininable de la existencia humana, sin la cual no existiría la vida del hombre. Es decir, el intercambio del hombre con la naturaleza es una determinación general y esencial de la vida humana, que trasciende por su carácter ontológico los modos de producción existentes y venideros. Cabe aclarar que esto significa, por un lado, que el trabajo ha existido y existirá en la vida humana como aquel "piso" necesario para la reproducción biológica y social del hombre 3 , y, por otro, que las formas concretas a partir de las cuales se organiza el proceso de metabolismo social adquieren rasgos históricos, es decir, que el modo en que se organiza el intercambio con la naturaleza varía históricamente, así como las relaciones entre los propios hombres.

Por lo tanto, aprehender la categoría trabajo en el modo de producción capitalista no significa abandonar aquellas categorías fundantes de la misma -la teleología, la causalidad puesta, la objetivación y la exteriorización- sino, por el contrario, aprehenderlas "en un complejo social que se mueve y reproduce procesualmente" (Lukács, 1981, p. 1).

En ese sentido, en el modo de producción capita-

2 Como advierte Lukács, "Cuanto más se desarrolla el trabajo, y con el la división del trabajo, tanto más autónomas se tornan las formas de las posiciones teleológicas de segundo tipo, y tanto más pueden desarrollarse en un complejo por sí de la división del trabajo. Esta tendencia evolutiva de la división del trabajo en la sociedad se encuentra, necesariamente, con el nacimiento de las clases: las posiciones teleológicas de este tipo, por vía espontánea o institucional, pueden ser puestas al servicio de un dominio, independiente de quien se sirva de esto; de aquí la frecuente ligación del trabajo intelectual, tornado autónomo, con los sistemas de dominación clasistas...” (1981, p. 18).

3 En torno a esta cuestión, Lukács afirma: "El ser social solo existe en su interrumpida reproducción...la transformación incesante en el curso de la reproducción produce continuamente los trazos substanciales especificos del ser social, en una escala cuantitativa y cualitativa cada vez más amplia. Como surgió de la naturaleza orgánica, el ser social conserva, por fuerza de las cosas, los trazos ontológicos permanentes de su origen. Este enlace entre las dos esferas... (se refiere a la esfera orgánica) es el hombre como ser biológico. Su reproducción -biológica- es no solo la inevitable premisa del ser social, sino también un polo del proceso reproductivo cuyo otro polo es constituido por la totalidad de la propia sociedad" (1981, p. 36). 
lista la relación social general se constituye en una unidad indirecta del trabajo social, donde a partir del trabajo privado, los productos libres e independientes de mercancías intercambian de modo conciente y voluntario sus mercancías. Es decir, la producción de mercancías es la condición a partir de la cual un individuo humano participa de la relación social general y mediante ella, puede obtener otros valores de uso que necesita para satisfacer sus necesidades.

Esto supone que la mercancía tiene la propiedad de ser al mismo tiempo un valor de uso y un valor, ya que en cuanto valor de uso es un objeto que satisface una necesidad humana. Sin embargo, el acceso indirecto a los productos del trabajo de la sociedad (trabajo social) genera que solo mediante el cambio el individuo puede acceder a los valores de uso necesarios para la reproducción de su vida. De allí que la mercancía es también un valor, donde productores libres e independientes intercambian sus respectivas mercancías por su valor, es decir, por el tiempo de trabajo socialmente necesario que lleva producir la misma, en cuanto tipo medio social.

Esta figura del productor libre e independiente de mercancías, con que se inicia la obra de Marx El Capital (2002), guarda cierta similitud con la concepción del ciudadano libre del Estado y comienza a adquirir mayor concreción en el devenir de la obra, ya que esta apariencia, de individuos que intercambian voluntariamente sus mercancías, es el resultado de un proceso de expropiación violento donde el productor es separado de los medios de producción, constituyendo al obrero doblemente libre, que "ni están incluidos directamente entre los medios de producción (...) ni tampoco le pertenecen a ellos los medios de producción (...) hallándose, por el contrario, libres y desembarazados de esos medios de producción" (Marx, 2004, p. 892-893).

Esto genera la existencia de una gran masa de desposeídos que, sin contar con los medios necesarios para trabajar, solo posee su fuerza de trabajo ${ }^{4}$ para ser vendida. Es por ello que el acto "voluntario y conciente" de aquellos que venden su fuerza de trabajo en el mercado encierra en sí y tiene por contenido la venta forzosa de la fuerza de trabajo, como la única posibilidad que tiene el obrero de reproducir su vida y, por otro lado, es necesario que aquellos poseedores de los medios de producción y de dinero adquieran dicha fuerza de trabajo. En torno a esta relación social, Marx señala que "él (por el obrero) y el poseedor de dinero se encuentran en el mercado y traban relaciones mutuas en calidad de poseedores de mercancías dotados de los mismos derechos, y de que solo se distinguen por ser el uno vendedor y el otro comprador; ambos, pues, son personas jurídicamente iguales" (2002, p. 205). La adquisición de la fuerza de trabajo en el mercado, a partir de la contratación del obrero por una cantidad de horas determinadas de trabajo, permite a aquella clase social poseedora de los medios de producción -la burguesía- poner en movimiento al "trabajo muerto", es decir a los medios de producción y la materia prima, con el "trabajo vivo", la fuerza de trabajo que convierte al capital constante en una mercancía específica. En esta relación contractual entre los poseedores de los medios de producción y los vendedores de fuerza de trabajo, el primero contrata al segundo para que realice un proceso de trabajo, esto quiere decir, produzca una objetivación que ya no le pertenece al individuo que transformó una porción de la realidad creando un objeto útil y que satisface necesidades humanas, sino que pertenece a quien lo contrató, a la burguesía.

Esta objetivación, que no pertenece a quien efectivamente produjo una transformación en la causalidad, volviéndola útil según finalidades humanas, comienza a ser desarrollada bajo el control del capitalista (que luego delega esta función de control en los supervisores y capataces), quien define en igual medida el proceso teleológico del proceso de trabajo, es decir, la finalidad y los medios necesarios para su consecución. Como sintetiza con precisión Lessa, este proceso de trabajo "deja de ser algo que, del inicio al fin, expresaba una determinada necesidad (...), una determinada elección (...) de un individuo determinado para ser expresión de una elección hecha por un individuo y llevada a la práctica por otro, con la finalidad de dar ganancia al patrón que no trabajó. Y el trabajador que ejecuta la orden del capitalista lo realiza como resultado de una coacción: la única forma del trabajador para sobrevivir bajo el capital es vender su fuerza de trabajo, a cambio de un salario, al burgués" (2011, p. 28).

La creciente mercantilización de la vida social, y en particular de la fuerza de trabajo, conduce a la consolidación de un trabajo alienado, que, a diferencia de aquel trabajo productor de valores de uso,

4 La fuerza de trabajo es "el conjunto de las facultades físicas y mentales que existen en la corporeidad, en la personalidad viva de un ser humano y que él pone en movimiento cuando produce valores de uso de cualquier índole” (Marx, 2002, p. 203). 
que permite crear los medios de vida del hombre y una creciente satisfacción de las necesidades humanas, tiene por objetivo producir "no solo un valor de uso, sino un valor, y no solo valor, sino además plusvalor" (Marx, 2002, p. 226).

La existencia de un plusvalor, esto quiere decir, de una mayor magnitud de valor que la originalmente desembolsada al inicio del trabajo, no supone que el capitalista se la apropie de manera forzosa o violenta al trabajador, sino que mediante la extensión de la jornada laboral o la intensificación del acto de trabajo se extiende el tiempo excedente de trabajo sobre el tiempo socialmente necesario de producción de la fuerza de trabajo. Es esta cualidad específica de la fuerza del trabajo la que busca el capitalista en el proceso de valorización de una mercancía, ya que "el valor de la fuerza de trabajo y su valorización en el proceso laboral son, pues, dos magnitudes diferentes. El capitalista tenía muy presente esa diferencia de valor cuando adquirió la fuerza de trabajo. Su propiedad útil, la de hacer hilado o botines, era solo una conditio sine qua non, porque para formar valor es necesario gastar trabajo de manera útil. Pero lo decisivo fue el valor de uso específico de esa mercancía, el de ser fuente de valor, y de más valor del que ella misma tiene" (2002, p. 234).

Esta forma histórica que adquiere el modo de organización del proceso de metabolismo social lleva de modo en sí mismo una creciente alienación del trabajo y de cosificación de las relaciones sociales, tanto en lo que respecta al proceso de objetivación del trabajo como de la objetivación misma, ya que no les pertenece al individuo que la produjo.

Esto significa que existe una diferencia entre el trabajo, como categoría fundante del ser social, y la forma histórica que adquiere en el capitalismo. Mientras la primera busca desarrollar las capacidades humanas ampliando el campo de alternativas concretas que el individuo puede desarrollar en la satisfacción de sus necesidades, en el trabajo alienado el fin último es la producción de plusvalía ${ }^{5}$ (Lessa, 2007b).

La constitución histórica del capitalismo como sociedad de clases, supone que esta se encuentra atravesada por la lucha de clases entre los intereses antagónicos del proletariado y la burguesía. Este enfrentamiento entre el capital y el trabajo, siendo esta la contradicción constitutiva del capitalismo, genera la necesidad de un conjunto de prácticas e instituciones que tienen por función social la reproducción de las relaciones sociales vigentes. Como advierte Lukács, "en la medida que el ser social se va sociabilizando, el dominio absoluto de la mera fuerza se atenúa, aunque nunca desaparece completamente en la sociedad de clases. Pues, cuando los antagonismos sociales ya adquieren formas más mediadas, reducir la regulación del actuar al puro uso de la fuerza significaría llegar, sin más, a la destrucción de la sociedad" (1981, p. 61-62).

En ese sentido, los complejos sociales tienen ciertas similitudes con el trabajo en lo que respecta a su forma (se objetivan posiciones teleológicas), a su materialidad (si bien pueden trabajar con distintos ambientes y herramientas, ambos se relacionan con la producción de bienes materiales, tanto en su fase de preparación como de transformación) y a ser trabajos asalariados. Sin embargo, la distinción central entre el trabajo y los complejos sociales se encuentra en la función social que desarrolla: si la primera tiene como finalidad la transformación de la naturaleza según finalidades humanas, la segunda interviene sobre las relaciones sociales, generando las condiciones necesarias para que el trabajo pueda efectivizarse y realizarse (Lessa, 2007c).

El propio Lukács hace referencia a que la transformación de la naturaleza por parte del hombre constituye las posiciones teleológicas primarias, existiendo también otras posiciones teleológicas, que denomina secundarias, cuyo "objeto de esta posición secundaria no es, pues, ya algo puramente natural, sino la conciencia de un grupo humano; la posición del fin ya no tiene por fin transformar un objeto natural, sino la ejecución de una posición teleológica que, por cierto, ya está orientada a objetos naturales; los medios, igualmente, ya no son intervenciones sobre objetos naturales, sino que quieren provocar tales intervenciones en otros hombres" (2004, p. 104).

Por lo tanto, el desarrollo de la sociabilidad humana fundada en el trabajo va generando un conjunto de complejos sociales que comienza a adquirir una autonomía (relativa) respecto al trabajo. Según Lukács, "la división del trabajo, en su expansión cuantitativa y cualitativa, crea cargos especiales, formas de mediaciones específicas entre complejos sociales singulares que, exactamente por causa de esta fun-

5 En palabras de Lessa "La finalidad del trabajo abstracto es la producción de plusvalía antes que la producción de los valores de uso necesarios a la vida humana. Esta sumisión de las necesidades humanas a las necesidades de la reproducción del capital es, sin embargo, apenas la expresión condensada de las alineaciones típicas del capital, y no cancela el hecho ontológico de que sin la transformación de la naturaleza en los medios de producción y subsistencia siquiera el capital podría existir" (2007b, p. 195). 
ción en el proceso reproductivo del complejo total, adquieren una peculiar estructura interna. Pero, justamente porque el funcionamiento correcto en un nivel superior del complejo total atribuye al complejo parcial mediador funciones parciales especificas, este asume cierta autonomía (...) un cierto modo autónomo y especifico de reaccionar y actuar (...)" (1981, p. 75). De este modo, diversos complejos sociales como el Estado, el Derecho, la Educación, los medios de comunicación, se constituyen en mecanismos coercitivos y de consenso que garantizan la reproducción de la sociabilidad capitalista.

Esta distinción entre el trabajo y los complejos sociales no supone que los segundos, por su autonomía, no tengan alguna mediación con el trabajo, es decir, con la posición teleológica y la transformación de la realidad mediante la objetivación. Sin embargo, los complejos sociales al actuar sobre las relaciones sociales se encuentran atravesados por intereses sociales contradictorios. Es por ello que para Lessa (2007c), el acto de trabajo requiere el conocimiento de los medios y fines destinados a transformar una posición de la naturaleza, mientras que los complejos sociales buscan desencadenar ciertas posiciones teleológicas en otros individuos, con lo cual son necesarios otros medios y fines, destacándose entre ellos la ideología.

Mediante este desarrollo, que ha permitido identificar las diferencias existentes entre la categoría trabajo y los complejos sociales, es posible afirmar que el Trabajo Social es uno de los complejos sociales que actúa sobre la reproducción de las relaciones sociales capitalistas vigentes. Es decir, en sus orígenes, la profesión formó (y actualmente forma) parte de las estrategias desarrolladas por la clase dominante en la fase monopólica del capitalismo para actuar sobre las refracciones de la "cuestión social", esto es, en los distintos problemas sociales que emergen como resultado de la lucha de clases entre el proletariado y la burguesía (Netto, 1997).

Este enfrentamiento entre las clases sociales fundamentales da origen a la "cuestión social", que según lamamoto es "expresión del proceso de formación y desarrollo de la clase obrera y de su ingreso en el escenario político de la sociedad exigiendo su reconocimiento como clase por parte de empresarios y del Estado. Es la manifestación, en lo cotidiano de la vida social, de la contradicción entre el proletariado y la burguesía, la cual pasa a exigir otros tipos de intervención, más allá de la caridad y de la represión. El Estado pasa a intervenir directamente en las relaciones entre el empresariado y la clase trabajadora, estableciendo no solo una reglamentación jurídica del mercado de trabajo, a través de la legislación social y laboral específicas, sino también interviniendo en la organización y prestación de los servicios sociales, como un nuevo tipo de enfrentamiento de la cuestión social" (1992, p. 91-92).

La constitución del proletariado como clase para sí comenzó a requerir del Estado no solo su actuación represiva, disolviendo manifestaciones, reprimiendo y rechazando las luchas y reivindicaciones obreras, sino también el desarrollo de diversas intervenciones sobre las manifestaciones de la "cuestión social". De este modo, el Estado comienza a enfrentarse ya no a situaciones puntales y concretas, sino a reivindicaciones de la población obrera. En ese sentido, Oliva señala que "el problema no era una cuestión estrictamente cuantitativa, sino que las respuestas merecieron un cambio cualitativo: el carácter colectivo de las demandas de la época, no permite que la dádiva puntual sea la forma de resolver las necesidades, sino que se requieren acciones más complejas para dar respuestas no a 'un' mendigo o 'un' desocupado inidentificable sino a la 'población entera" (2007a, p. 16).

Este accionar del Estado coincide con la fase del capitalismo en su etapa imperialista, donde la manutención de la tasa de ganancia del capital requiere de mecanismos extraeconómicos, revitalizando el accionar del Estado, no solo en su función de resguardo de la propiedad privada, sino también en su imbricación con sus funciones políticas. En palabras de Netto "el capitalismo monopolista, por su dinámica y contradicciones, crea condiciones tales que el Estado por él capturado es permeable a demandas de las clases subalternas, que pueden hacer incidir en él sus intereses y sus reivindicaciones inmediatas. Y que este proceso está en su conjunto tensionado no solo por las exigencias del orden monopólico, sino también por los conflictos que este hace emanar en toda la escala societaria" (1997, p. 18).

En este marco, el Estado comienza a desarrollar de modo sistemático una intervención sobre las manifestaciones de la "cuestión social", a través de políticas sociales ${ }^{6}$. Este accionar del Estado está

6 Pastorini (2000) señala que las políticas sociales son el resultado de las relaciones antagónicas entre el Estado, las clases subalternas y las clases hegemónicas. Por ende, son tanto concesiones del Estado y del capital como así también conquistas de la clase trabajadora. Al mismo tiempo, la autora recalca la función política-como mecanismo legitimador del orden-y económica-abaratamiento de la fuerza de trabajo, mediante la socialización de los costos de producción- de las políticas sociales. 
dirigido a actuar sobre los efectos de la "cuestión social", sobre sus refracciones y no sobre la causa de la misma. De allí que Netto (1997) refiera que este accionar se estructura mediante la fragmentación y parcialización de la "cuestión social", conformando recortes abstractos que intervengan sobre problemas sociales puntuales.

El creciente accionar de la clase obrera requirió de una progresiva intervención del Estado sobre las manifestaciones de la "cuestión social" y la constitución, no solo de instituciones que abordaran los distintos problemas sociales, sino también de profesionales que actuaran sobre los mismos, entre los que se encontraba el trabajador social.

En síntesis, en el marco del desarrollo del capitalismo en su fase imperialista, el Trabajo Social emerge como uno de los complejos sociales motorizados por la clase burguesa para actuar y armonizar los conflictos sociales. Mediante estos planteos, es posible comprender que el Trabajo Social sea demandado como una profesión, inscrita en la división sociotécnica del trabajo, siendo esta una de las formas institucionalizadas por el Estado para regular y atender las refracciones de la "cuestión social", y cuya función asignada es la reproducción de la fuerza de trabajo y la transmisión de la ideología de la clase dominante. En ese sentido, el trabajo profesional del trabajador social se enfrenta a la contradicción de responder a intereses y necesidades de las clases antagónicas, reforzando las condiciones de dominación sobre las clases subalternas, y de participar al mismo tiempo de las respuestas a las necesidades mínimas e indispensables de la clase trabajadora ${ }^{7}$.

A continuación, en el siguiente apartado, se pretende hacer un análisis crítico de aquellos planteos posmodernos en Trabajo Social, indagando qué elementos proponen para la intervención profesional, específicamente en lo que respecta a la dimensión teleológica, en la determinación de los medios y los fines y, al mismo tiempo, plantear cuáles serían desde una perspectiva marxista, algunas de las determinaciones fundamentales para conformar estrategias de intervención profesional que superen la mera inmediatez fenoménica que se presenta en el cotidiano.

\section{La teleología en el Trabajo Social}

Antes de introducir la discusión central de este último apartado, es necesario realizar algunas precisiones en torno al Trabajo Social como complejo social. Como ya fue expuesto con anterioridad, el trabajo es la categoría fundante del ser social y, en un sentido específico, remite al intercambio entre el hombre y la naturaleza, donde la objetivación del trabajo conduce a nuevas necesidades y posibilidades en la vida humana. Es por ello que el trabajo es el modelo de la praxis social, la categoría fundante del ser social, lo que no implica que el accionar humano se limite a él, sino que al mismo tiempo van desarrollándose diversos complejos sociales ya presentes en el trabajo más primitivo, como el lenguaje, la cooperación, entre otros- que de forma espontánea o institucional van adquiriendo una autonomía relativa frente al trabajo, es decir, de lo que Lukács (1981) llama el complejo económico.

Si la función social del trabajo es generar los medios de producción y subsistencia del ser social, los complejos sociales están dirigidos a actuar sobre las relaciones sociales vigentes, es decir, interviene en los vínculos desarrollados por los propios hombres. La teleología secundaria de los complejos sociales es "un tipo de acción que opera en las relaciones sociales y humanas incidiendo sobre los actos de conciencia de los individuos y grupos, movilizando fuerzas psíquicas en base a valor, hábitos, actitudes, normas sociales, procesos educativos, políticos y otros más. Según Lukács, en estas posiciones secundarias el 'material' de la posición del fin es el hombre, sus relaciones, sus ideas, sus sentimientos, su voluntad, sus aptitudes. Así, se trata de un campo "cualitativamente más oscilante (...) imprevisible que en el trabajo" (Costa, 2000, 10).

Esta distinción que realiza Lukács $(1981,2004)$ entre el trabajo y los complejos sociales, esto es, entre las posiciones teleológicas primarias y secundarias, hace alusión a que el primero actúa sobre una causalidad dada, que en general reproduce procesos físico-químicos, mientras que la segunda, actúa sobre un nivel del ser (el ser social) que siempre tiene un margen de libertad y acción ${ }^{8}$, ya que ante

7 Este carácter contradictorio de la intervención profesional puede ser objeto de una direccionalidad por parte del profesional, fortaleciendo los intereses de una clase sobre otra. En ese sentido, señala: “... la actuación del Trabajador Social(...) reproduce también, por la misma actividad, intereses contrapuestos que conviven en tensión. Responde tanto a las demandas del capital como a las del trabajo y solo puede fortalecer uno u otro polo por la mediación de su opuesto. Participa tanto de los mecanismos de dominación y explotación como también, al mismo tiempo y por la misma actividad, da respuesta a las necesidades de sobrevivencia de la clase trabajadora y de la reproducción del antagonismo en esos intereses sociales, reforzando las contradicciones que constituyen el móvil básico de la historia. A partir de esa comprensión es que se puede establecer una estrategia profesional y política para fortalecer las metas del capital o del trabajo" (Iamamoto, 1992, p. 89).

8 Como reconoce Lukács, en todo acto humano siempre "(...) se conserva un mínimo de libertad en la decisión; también aquí se trata -como caso límite- de una alternativa y no de un acontecimiento natural determinado por una causalidad puramente espontánea” (2004, p. 168). 
cada decisión el individuo tiene una pluralidad de alternativas.

Es por ello que la función social que desempeñan el trabajo y los complejos sociales genera que la operatividad de los mismos sea esencialmente distinta, dificultando la anteposición de categorías vinculadas al proceso de trabajo, como el objeto de trabajo, los medios o instrumentos de producción y el producto a los complejos sociales. Como recalca Lessa, considerar a "la 'cuestión social' como 'materia prima' (supone) igualar la objetividad compuesta por la causalidad puesta (esto es, la porción del mundo objetivo construido por los seres humanos) con la causalidad dada de la naturaleza (...). Pues la materia natural, por ser la más pura causalidad jamás permeada por los complejos ideológicos, requiere para su transformación actos ontológicos distintos de los actos que actúan sobre las relaciones sociales" (2007c: 77-78).

De igual modo, el trabajo genera como producto una objetividad (sea bajo su forma de medios de producción o de subsistencia) que perdura independientemente de la actividad productiva que la realiza. Es por ello que el Trabajo Social es un complejo social que actúa sobre diversas situaciones problemáticas presentes en la vida cotidiana de amplios segmentos de la población.

Para Costa (2000), el Trabajo Social sería un complejo social de carácter ideológico, en un sentido estricto, al actuar sobre diversos problemas sociales, en cuanto refracciones de la "cuestión social", que busca resolver aquellos conflictos sociales latentes o explícitos. Pero también en un sentido amplio de ideología, al permitirle a la profesión, desde su posicionamiento teórico y político, producir mediaciones de las situaciones singulares con la totalidad, es decir, desarrollar mediaciones entre el individuo y el género humano, entre proyectos profesionales y proyectos societarios.

Estas consideraciones teóricas permiten aprehender al Trabajo Social como un complejo social que actúa sobre las refracciones de la "cuestión social", esto es, sobre los problemas sociales presentes en diversos segmentos de la población. Por el lugar que ocupa en la división social del trabajo, el Trabajo Social desarrolla posiciones teleológicas secundarias dirigidas a intervenir sobre la vida cotidiana de las clases subalternas.

Someramente, el cotidiano podría ser caracterizado por su carácter heterogéneo, esto es, por la coexistencia y diferentes actividades y demandas en las que el hombre se objetiva, por su inmediatez, ya que las respuestas dadas a la misma suponen una relación directa entre pensamiento y acción y por su superficialidad extensiva, ya que la relación entre teleología y objetivación impide conocer la mayoría de las determinaciones presentes en cada situación (Netto, 1994). Como sintetiza Lukács, en el cotidiano se "plantea ininterrumpidamente alternativas que aparecen en forma inesperada, y que a menudo tienen que ser respondidas de inmediato bajo amenaza de ruina; una determinación esencial de la propia alternativa es que la decisión debe ser tomada sin que se conozcan la mayoría de los componentes, la situación, las consecuencias, etc." (2004, p. 168).

Estas determinaciones, se encuentran presentes en el propio cotidiano del accionar profesional, cuando se promueven respuestas directas entre el pensar y el actuar, cuando las múltiples y diversas demandas absorben al profesional sin poder direccionar su intervención o cuando se dificulta la captación de las determinaciones universales en el escenario institucional y de la intervención concreta.

Como advierte Guerra, en las funciones asignadas al Trabajo Social, destinadas a ejecutar y operacionalizar las políticas sociales, en el horizonte de su accionar profesional, ligado a las condiciones objetivas y subjetivas de las clases subalternas y las modalidades interventivas que requieren un accionar segmentado sobre los problemas sociales, se hayan presente "respuestas manipuladoras, fragmentarias, inmediatistas, aisladas, individuales, tratadas en sus expresiones/apariencias (y no en las determinaciones fundacionales), cuyo criterio es la promoción de una alteración en el contexto empírico, en los procesos segmentados y superficiales de la realidad social, cuyo parámetro de competencia es la eficacia según la racionalidad burguesa. Son operaciones realizadas por acciones instrumentales, son respuestas operativo-instrumentales en las que impera una relación directa entre pensamiento y acción, y una ruptura entre medios (valores e instrumental técnico) y fines. Abstraídas de mediaciones subjetivas y universalizantes (referenciales teóricos, éticos, políticos, socio-profesionales, tales como los valores colectivos), estas respuestas tienden a que se perciban las situaciones sociales como problemáticas individuales (por ejemplo, el caso individual, la situación existencial problematizada, las problemáticas de orden moral y/o personal, las patologías individuales, etc.)" (2007: 260).

En otras palabras, estas determinaciones presentes en el cotidiano aparecen en la intervención profesional al ocultarse, mediante las capas epidérmicas 
y fenoménicas de los problemas sociales que se le presentan al profesional, la actuación sobre los conflictos producidos en el marco de la lucha de clases de la sociedad capitalista. Es decir, las posiciones teleológicas secundarias de la intervención profesional adoptan acríticamente la finalidad planteada por la institución empleadora del profesional, sin poder diferenciarla de las estrategias de intervención profesional que apuntan a lograr una mayor autonomía relativa dentro de la institución con miras a la consecución de finalidades interventivas que fortalezcan los derechos sociales y su efectivización (Pontes, 1995).

Frente a esto, surgen una serie de interrogantes ligados al Trabajo Social y a la posición teleológica que este desarrolla: ¿Es posible desarrollar una posición teleológica secundaria en la intervención profesional que logre superar la "teleología impuesta" por la institución empleadora en la que se encuentra inserto el profesional? ¿Qué límites y posibilidades existen en dicha intervención profesional? ¿Cómo aprehenderlas? ¿Cuáles son algunas de las determinaciones fundamentales que permitirían definir una finalidad interventiva orientada a lograr la efectivización de los derechos sociales y cuyo horizonte es la emancipación humana?

Estos interrogantes son posibles de ser formulados en la medida en que desde una perspectiva histórico-crítica se afirma que toda situación concreta, inclusive aquellas presentes en los procesos de intervención profesional, dejan un margen de libertad al individuo para decidir entre un conjunto de alternativas presentes en la realidad, que permiten desarrollar el paso de la potencialidad a la realidad, al actuar sobre esta última. Pero la aprehensión de dichas alternativas, que son evaluadas a partir de la finalidad planteada, en el caso del Trabajo Social, requiere necesariamente un proceso de investigación que aprehenda las determinaciones presentes en la realidad, de modo tal que sea posible desarrollar una crítica de la vida cotidiana, que siempre demanda respuestas de corte inmediatista y fragmentarios.

La superación de esta identidad entre la finalidad institucional ${ }^{9}$ y la finalidad del profesional requiere de un proceso analítico que apunte a la aprehensión de las determinaciones y mediaciones socio-históricas presentes en las situaciones cotidianas a las que el profesional se enfrenta, reconstruyendo las mis- mas como expresiones de la "cuestión social". De allí que sean centrales los aportes de Lukács (2004) para pensar a partir de la categoría teleología los procesos interventivos del Trabajo Social, no solo porque toda acción humana es antecedida por una posición teleológica, sino también, porque la misma, al no ser un epifenómeno de la naturaleza que actúa de modo inmediato sobre el medio, requiere de un proceso de investigación de los medios y de la finalidad, para aprehender en la realidad concreta las alternativas de acción.

La investigación de la finalidad y de los medios significa un proceso de aproximación y reconstrucción de la realidad de carácter provisorio, que apunta a reorientar y redefinir los procesos teleológicos secundarios presentes en la intervención profesional, definiendo cuáles son los valores que el profesional sustentará en su accionar profesional y cuál es el deber ser que orienta dicho accionar, que busca concretizarse mediante la conformación de estrategias de intervención. Es decir, solo mediante la conformación de estrategias de intervención profesional situadas, que aprehendan el significado social de la profesión y las tensiones presentes en el ámbito particular de trabajo, es posible direccionar la propia intervención profesional.

Para ello, resulta fundamental que los hechos singulares y aislados que se presentan en la intervención profesional sean reconstruidos a partir de sucesivas mediaciones, como partes de una totalidad más amplia que las contiene. Como resalta Kosik, cada situación social se caracteriza "de un lado, por definirse a sí mismo, y, de otro lado, definir al conjunto; ser simultáneamente productor y producto; ser determinante, y, a la vez, determinado; ser revelador y, a un tiempo, descifrarse a sí mismo; adquirir su propio auténtico significado y conferir sentido a algo distinto. Esta interdependencia y mediación de la parte y del todo significa al mismo tiempo que los hechos aislados son abstracciones, elementos artificiosamente separados del conjunto, que únicamente mediante su acoplamiento al conjunto correspondiente adquieren veracidad y concreción" (1965, p. 61).

Esto significa que cada situación concreta a la que se enfrenta el profesional necesariamente remite a un conjunto de determinaciones y mediaciones más amplias que la contienen. La superación del cotidiano desde una visión de totalidad apunta a reconstruir los problemas sociales y las situaciones

9 Para Pontes "La demanda institucional aparece en el intelecto del profesional desprovista de mediaciones, parametrizada por objetivos técnico-operativos, metas y una forma dada de inserción especial (...) programática (...) o poblacional. En una palabra, la demanda institucional aparece ligada a la inmediaticidad, como un 'fin en sí mismo'” (1995, p. 168). 
que se presentan en la intervención desde sucesivas aproximaciones que capten la génesis y estructura de los mismos. Para ello, las mediaciones, en cuanto categorías ontológico-reflexivas ${ }^{10}$ son esenciales para comprender el movimiento de lo real.

En la dialéctica de lo singular y lo universal se encuentra la clave para conocer el modo de ser del ser social: lo particular. Dicha categoría permite comprender la mediación entre los hombres singulares y la sociedad, donde se supera la inmediatez y el "aislamiento" del hombre singular al mismo tiempo que las leyes tendenciales que actúan a nivel universal de la sociedad (como la relación capital-trabajo; el papel del Estado, etc.) cobran formas particulares. Como recalca Pontes, la aprehensión de lo particular en la intervención profesional permite "que las leyes tendenciales, que son capturadas por la razón en la esfera de la universalidad, como las leyes del mercado, relaciones políticas de dominación etc., actúan como si tomasen vida, se objetivasen y se hiciesen presentes en la realidad singular de las relaciones sociales cotidianas, desingularizándolas y transformando lo que era universal en particular, sin perder su carácter de universal ni su dimensión de singularidad" (2003, p. 216).

Mediante sucesivas aproximaciones, el profesional puede resignificar la demanda institucional, mediándola con complejos sociales más amplios que la determinan, y que en su interrelación adquieren sentido y significado. Por un lado, esto contribuye a que el profesional no caiga en miradas inmediatistas que apuntan a actuar sobre el individuo a partir de la psicologización de sus problemas sociales y cuyo horizonte es la "integración social de este individuo". Por otro lado, la perspectiva de totalidad y la captura de lo particular permiten la construcción de estrategias de intervención situadas, en las que coexisten sujetos con intereses antagónicos y en el marco de un momento y lugar específico y bajo una coyuntura de fuerzas dinámica y cambiante.

Así, la intervención profesional debe partir de una reconstrucción del escenario de la intervención, que necesariamente remite a la comprensión de la institución en la que se encuentra inserto, a cuáles son los objetivos y finalidades que plantea a nivel general y, particularmente para el trabajador social, cuáles son los sujetos intervinientes en la misma, qué intereses y posiciones desarrollan y cuál es el lugar que ocupa el profesional dentro de la institu- ción y en la interacción con los sujetos colectivos. Solo de este modo es posible desarrollar una distinción entre una "teleología atribuida" al trabajador social por la institución en la que trabaja y el desarrollo de una posición teleológica secundaria que mediante la determinación de una finalidad (vinculada a un proyecto profesional ético-político y a proyecto societario emancipatorio) y la investigación de los medios, pueda objetivar una cadena de alternativas que oriente a ampliar la autonomía relativa que el profesional tiene en la institución y que apunte a la consecución de los derechos sociales de la población usuaria.

Esta posición teleológica secundaria, propia de la intervención profesional, debe dirigirse a aprehender un conjunto de determinaciones y mediaciones ligadas centralmente a tres dimensiones.

La primera de ellas es la dimensión socio-institucional (Mallardi 2004, Gianna y Mallardi, 2011) que apunta a reconstruir los nexos entre el rol que desempeña el Estado en la atención de las manifestaciones de la "cuestión social" a partir de las políticas sociales y las formas en que estas se presentan en la dinámica institucional, tanto en la construcción de la demanda institucional como en los recursos asequibles para ello. Esta dimensión debe reconocer que la "...intervención estatal sobre la "cuestión social" se realiza... fragmentándola y parcializándola” (Netto, 1997: 22), borrando cuál es la génesis de los problemas sociales -la explotación de la fuerza de trabajo y el antagonismo de clases- y priorizando respuestas múltiples y diversas entre sí, como un "calidoscopio" de problemas sociales y respuestas dispersas.

Junto a estas determinaciones más generales, que también incluyen el análisis ligado a las "inducciones comportamentales" (Netto, 1997) que las políticas sociales traen consigo, es necesario analizar otras determinaciones presentes en la intervención profesional. Uno de estos elementos es el marco jurídico existente y/o vinculado a alguna de las manifestaciones de la "cuestión social", el mismo no solo se limita a aquellas normas y leyes que pueden estar vinculadas al campo específico de la intervención profesional y que son centrales que el profesional conozca y maneje, sino que también es necesario incorporar el conocimiento de otras leyes que pueden ser instrumentos para demandar la efectivización y cumplimiento de determinados derechos sociales.

Por otra parte, para lograr un proceso de diferen-

10Las mediaciones son ontológicas; ya que son "expresiones históricas de las relaciones que el hombre edificó con la naturaleza y consecuentemente de las relaciones sociales de ahi derivadas, en las varias formaciones socio-históricas que la historia registró" (Pontes, 1995, p. 78). 
ciación respecto a la demanda institucional, resulta primordial conocer cuáles son las finalidades presentes en la institución y/o en la política social que se ejecuta. En ese sentido, el análisis sobre los objetivos ligados a la reproducción material y espiritual de la población usuaria implica también un análisis de los recursos que la institución tiene disponibles en ese momento. Que dichos recursos, como advierte Oliva (2007b), sean asequibles o inasequibles en un momento determinado, no depende de que los mismos sean escasos, sino de las determinaciones más generales vinculadas al orden social. Los mismos, centralmente se encuentran ligados a los recursos profesionales y aquellos, a prestaciones. Finalmente, en esta dimensión es central el análisis de la cobertura de la población que la institución y/o la política social contiene. Siendo estos criterios, sean económicos o de reconocimiento, una modalidad de recorte y fragmentación de la "cuestión social".

La segunda dimensión refiere en la subdeterminante popular. La misma hace alusión a la capacidad objetiva que tiene la clase trabajadora de incidir en las instancias hegemónicas que regulan la "cuestión social". Entre ellas, se encuentran las instituciones y las políticas sociales donde el trabajador social se encuentra inserto, como partes de una estrategia de hegemonía de la clase dominante que articula al mismo tiempo los intereses de la burguesía y ciertas concesiones-conquistas de la clase trabajadora.

Es necesario incorporar dentro de la teleología, la reconstrucción de los posicionamientos e intereses que sostienen las clases subalternas, en la medida en que habilita la construcción de alianzas con estos sectores, de modo de incidir colectivamente en la institución empleadora del trabajador social, introduciendo nuevas necesidades y demandas en la misma y, de igual modo, permitir al profesional incorporar en el seno de la institución algunas de las posiciones, críticas y visiones que tiene la población en torno a la misma. En síntesis, esta dimensión supone que "además de la consideración que pueda tener el profesional de la población usuaria importa considerar las fuerzas objetivas que este tenga al momento de presentarse frente al trabajador social y subdeterminar su práctica. De esta manera, la capacidad de presión que la población usuaria tenga para incidir en los procesos de intervención, se corresponderá con el posicionamiento que la clase trabajadora tenga en la correlación de fuerzas vigentes en el contexto en el cual se desarrollan dichos procesos" (Gianna y Mallardi, 2011, p. 10).

Finalmente, la tercera dimensión refiere a lo éticopolítico. Ya Lukács (2004) muestra cómo la posición teleológica, al determinar la finalidad, hace surgir un deber ser. El mismo solo tiene existencia dentro de la vida humana, ya que en la vida orgánica siempre el presente está determinado por el pasado, mientras que en el ser social, "la posición del fin invierte, como hemos visto, esta relación: el fin está (en la conciencia) antes de su realización, y en el proceso que conduce a dicha realización, cada paso, cada movimiento es guiado por la posición del fin (por el futuro)" (Lukács, 2004, p. 121).

Este debe ser orienta el accionar del individuo en el proceso de objetivación, incluyendo la valorización que realiza el mismo en torno a la finalidad planteada y la objetivación. Esto quiere decir que la génesis de los valores sociales se encuentra para Lukács en el acto de trabajo, mediante la determinación de la utilidad o inutilidad, lo verdadero o falso. Esta génesis del valor, que se encuentra en el trabajo y el desarrollo de las capacidades humanas, dio lugar a la ética "entendida como "un momento de la praxis humana en su conjunto' (...) la ética no es ninguna dimensión o esfera específica de la realidad, objetivándose, teórica y prácticamente, de formas particulares y socialmente determinadas, como conexión entre el individuo singular y las exigencias sociales y humano genéricas" (Barroco, 2008, p. 29).

La ética permite incorporar dentro de los procesos teleológicos de la profesión la mediación entre lo singular y lo humano-genérico, vinculado a qué valores éticos sustenta la profesión y en que proyectos políticos pueden efectivizarse los mismos. Esta forma de comprender la ética reconoce que la misma no se encuentra limitada a un código de ética normativo, sino que atraviesa a la intervención profesional en su totalidad, en la dimensión teórica, práctica y política. Es por ello que para Barroco (2004), la ética profesional se liga a una esfera teórica, que sienta las bases filosóficas a partir de las cuales comprender al hombre y la sociedad, lo que permite reflexionar teóricamente sobre la ética y los valores que deben ser sustentados y defendidos por la profesión.

Esta dimensión necesariamente requiere de un nivel de construcción colectivo ${ }^{11}$ en el cual la profesión

11 Este nivel colectivo significa la construcción de "la auto-imagen de una profesión, eligen valores que la legitiman socialmente, delimitan y dan prioridad a sus objetivos y funciones, formulan los requisitos (teóricos, institucionales, y prácticos) para su ejercicio, prescriben normas para el comportamiento de los profesionales y establecen las bases de su relación con los usuarios de sus servicios, con las otras profesiones y con las organizaciones e instituciones sociales privadas y públicas (entre estas, también y destacadamente el Estado, al que cabe históricamente el reconocimiento jurídico de los estatutos profesionales)" (Netto, 2003, p. 274-275). 
determina cuál es la direccionalidad ética y política sostenida por la misma, así como cuáles son las mediaciones que establece con los proyectos societarios en pugna. Pero también, esto requiere que el proyecto ético-político profesional, en cuanto teleología, sea objetivado en los procesos concretos de intervención profesional.

A partir de este recorrido, en este tercer punto se ha planteado cómo la comprensión del Trabajo Social como complejo social que desarrolla posiciones teleológicas secundarias es una de las determinaciones centrales para comprender cuáles son las particularidades que atraviesan la intervención profesional. Mediante la recuperación de la categoría teleología, y el carácter particular que esta adopta en el Trabajo Social (teleología secundaria), se ha avanzado sobre cómo desarrollar un proceso de aprehensión de las determinaciones presentes en la intervención profesional, que contribuyan a conformar estrategias de intervención profesional que superen la inmediatez y contribuyan a fortalecer la posición de las clases subalternas en las instituciones.

\section{Consideraciones finales}

Mediante estas reflexiones se ha buscado mostrar cómo el pensamiento teórico de Lukács es un interlocutor fecundo para pensar y analizar las determinaciones presentes en el Trabajo Social contemporáneo. Es por ello que se han recuperado de este autor sus consideraciones en torno al trabajo como categoría que da origen al ser social y que progresivamente lo va distinguiendo de las otras esferas del ser, a partir de su capacidad de dar respuestas cada vez más mediadas.

En ese sentido, abordar la distinción ontológica existente entre el trabajo y los complejos sociales contribuye a develar cuáles son las particularidades presentes en el Trabajo Social, considerándolo como uno de los complejos sociales movilizados por la burguesía para reproducir el orden social vigente.

El reconocimiento de este lugar objetivo dentro de la división social del trabajo no significa que la profesión, de modo determinista, únicamente reproduzca el orden vigente, sino que, mediante la comprensión del significado social de la profesión y del espacio laboral concreto en que se inserta el profesional, es posible encontrar espacios que aumenten la autonomía relativa, nuevas alternativas que solo pueden ser aprehendidas mediante una comprensión permanente de la realidad.

Es allí cuando la construcción de estrategias de intervención debe apuntar a superar la inmedia- tez fetichizada del cotidiano capitalista, superando aquella identificación entre las finalidades institucionales y las finalidades propias del profesional.

El desafío de la intervención profesional se encuentra en profundizar su teleología secundaria, mediante la definición de las finalidades y del análisis de los medios necesarios para su consecución, logrando de esta manera una diferenciación con la teleología definida por la institución. Este proceso requiere que el profesional defina y construya estrategias de intervención profesional, pero siempre considerando que estas no están determinadas "únicamente por el posicionamiento del Trabajador Social, ni por la dirección política de la institución, ni por los usuarios, sino por una compleja y dinámica relación que está determinada por diversos recursos, mediados por una articulación que se condensa en el arsenal operativo en un momento histórico determinado" (Oliva, 2007b: 15).

\section{Bibliografía}

- BARroco, M. L. (2004). Ética y Servicio Social: fundamentos ontológicos ( $1^{\mathrm{a}} \mathrm{ed}$.). Brasil: Cortez Editora.

- BARROCO, M. L. (2008). Ética: fundamentos socio-históricos ( $1^{\mathrm{a}} \mathrm{ed}$.). Brasil: Cortez Editora.

- COSTA, G. (2000). Aproximaçao ao Serviço Social como complejo ideológico, Revista Temporalis, v.1, n. 2.

- GiannA, S. Y MALlaRdi, M. (2011) El trabajo social como complejo social. Aproximación a los fundamentos de los procesos de intervención profesional, Revista Debate e Sociedade, $\mathrm{N}^{\circ} 1$. Disponible en: http://200.233.146.122:81/revistadigital/index.php/ debatesociedade/index

- GUerRA, Y. (2007). El proyecto profesional crítico: estrategia de enfrentamiento de las condiciones contemporáneas de la práctica profesional. En: La profesionalización en trabajo social. Rupturas y continuidades, de la reconceptualización a la construcción de proyectos ético-políticos ( $1^{\mathrm{a}}$ ed.). Rozas Pagaza M. (Coord.). Argentina: Espacio Editorial.

- iamamoto, M. (1992). Servicio Social y división del trabajo ( $1^{\mathrm{a}}$ ed.). Brasil: Cortez Editora.

- KOFLER y otros (1971). Conservaciones con Lukács (2a ed.). España: Alianza Editorial.

- KOSIK, K. (1965). Dialéctica de lo concreto (1ª ed.). México: Editorial Grijalbo.

- LESSA, S. (2002). Mundo dos homens. Trabalho e ser social ( $1^{a}$ ed.). Brasil: Boitempo editorial.

- LESSA, S. (2007a). Para compreender a ontologia de Lukács ( $3^{a}$ ed.). Brasil: Editora Unijui.

- LESSA, S. (2007b). Trabalho e proletariado no capitalismo contemporâneo ( $1^{\text {a }}$ ed.). Brasil: Cortez Editora. 
- LESSA, S. (2007c). Serviço Social e Trabalho: porque o serviço social não é trabalho. (1 $1^{a}$ ed.). Brasil: EDUFAL.

- LESSA, S. (2011). El proceso de producción/reproducción social: trabajo y sociabilidad. En: Cuestión Social, reproducción de la fuerza de trabajo y políticas de asistencia ( $1^{\text {a }}$ ed.). Mallardi M; Madrid L.; Oliva A. (Comp.). Argentina: Universidad Nacional del Centro de Buenos Aires.

- LUKÁCS, G. (1981). Ontología del ser social. Capítulo: La reproducción. Traducción de Sergio Lessa. Consultado: Julio 2011. Disponible en: www.sergiolessa.com

- LUKÁCS, G. (2004). Ontología del ser social: El trabajo ( $1^{a}$ ed.). Argentina: Ediciones Herramientas.

- MALlardi, M. (2004). La entrevista en Trabajo Social. Diálogos con la Filosofía Bajtiniana. Tandil, Tesis de Grado de la Carrera de Trabajo Social-FCH-UNCPBA.

- MARX, K. (2002). El Capital. Crítica de la economía política. Tomo I Volumen 1. (1 $1^{\text {a }}$ ed.). Argentina: Siglo XXI editores.

- MARX, K. (2004). El Capital. Crítica de la economía política. Tomo I Volumen 3. ( $1^{\text {a }}$ ed.). Argentina: Siglo XXI editores.

- MARX K; ENGELS F. (1959). La Ideología Alemana (1 ed.). Uruguay: Ediciones Pueblos Unidos.

- NETTO, J.P. (1994). Cotidiano: conhecimiento e crítica ( $3^{a}$ ed.). Brasil: Cortez Editora.

- NETTO, J. P. (1997). Capitalismo monopolista y servicio social ( $1^{a}$ ed.). Brasil: Cortez Editora.

- NETTO J.P; BRAZ M. (2006). Economia política. Uma introduçao crítica ( $1^{a}$ ed.). Brasil: Cortez Editora.

- Oliva, A. (2007a). Análisis histórico de las modalidades de intervención en Argentina. Trabajo Social y lucha de clases ( $1^{\text {a }}$ ed.). Argentina: Editorial Imago Mundi.

- OLIVA, A. (2007b). Los recursos en la intervención profesional del trabajador social ( $1^{\text {a }}$ ed.). Argentina: Ediciones Cooperativas.

- PAStorini, A. (2000). ¿Quién mueve los hilos de las políticas sociales? Avances y límites en la categoría "concesión-conquista". En: La política social hoy (1 ed.). Borgianni E., Montaño C. (Orgs.). Brasil: Cortez Editora.

- PONTES, R. (1995). Mediaçao e serviço social. Um estudo preliminar sobre a categoria teórica e sua apropiaçao pelo Serviço Social (1 ${ }^{\mathrm{a}}$ ed.). Brasil: Cortez Editora.

- PONTES, R. (2003). Mediación: categoría fundamental para el trabajo del asistente social. En: Servicio Social crítico. Hacia la construcción del nuevo proyecto éticopolítico profesional ( $1^{\text {a }}$ edición). Borgianni E.; Guerra Y.; Montaño C. (Orgs.) Brasil: Cortez Editora. 